\title{
Diurnal Changes in Photosynthetic Efficiency and Carotenoid Composition of the Lichen Anaptychia ciliaris: Effects of Hydration and Light Intensity
}

FERNANDO VALLADARES

Centro de Ciencias Medioambientales, CSIC, Serrano 115 dup., E-28006 Madrid, Spain. Present address: Division of Biological Sciences, Section of Plant Biology, University of California, Davis, CA 95616, USA

Amparo SANChez-Hoyos AND Esteban MANRIQUE

Departamento de Biología Vegetal II, Facultad de Farmacia, Universidad Complutense de Madrid, E-28040 Madrid, Spain

Abstract. Diurnal changes in chlorophyll fluorescence and carotenoid composition were studied in artificially hydrated thalli of the lichen Anaptychia ciliaris to assess the concomitant variations in photosynthetic efficiency and xanthophyll cycle associated energy dissipation under contrasting light conditions. One group of thalli was kept continuously wet (over $50 \%$ of maximum water content) while another was kept dry and hydrated only 15 minutes before each measurement. Half of the thalli of each group were kept in the shade (natural environment) while the other half were exposed to direct sunlight. The photochemical efficiency of photosystem II (assessed by the fluorescence parameter $F v / F m$ ) decreased significantly towards the end of the day in thalli of A. ciliaris kept wet under direct sunlight, but not in wet, shaded thalli. The relative proportions of antheraxanthin (A) and zeaxanthin (Z) of wet thalli exposed to direct sunlight showed a significant increase in the afternoon and a sharp decrease during the evening. Dry thalli hydrated just 15 minutes before the measurements showed similar diurnal changes in Fv/Fm and in the relative proportions of $A+Z$ to the continuously wet thalli under the same light environment. Predawn data from naturally dried thalli indicated a sustained high proportion of $A+Z$ that accounted for a relatively low photochemical efficiency at the beginning of the experiments.

Absorption of more light by plants than can be utilized in photosynthesis may lead to photo-oxidative destruction of the photosynthetic apparatus (Powles 1984). The inhibition of photosynthesis when light absorption exceeds photochemical utilization (photoinhibition) has been well documented for a wide variety of plants (Baker \& Bowyer 1994) including lichens (Coxson 1987a, $b$; Kappen et al. 1991; Manrique et al. 1993). Photoinhibition has been classified in two main classes on the basis of relaxation times: dynamic photoinhibition or photosynthetic down regulation, a readily reversible process that provides photon protection to photosystem II (PS II), and chronic photoinhibition, a slowly reversible depression of photosynthesis associated with photon damage (Osmond 1994). Dynamic photoinhibition in plants acclimated to high radiation is thought to be due to a dissipation of a fraction of the excitation energy through the xanthophyll cycle (Demmig et al. 1987). The xanthophyll cycle in higher plants and green algae consists of conversion of the diepoxide violaxanthin to the epoxide-free zeaxanthin, via the monoepoxide antheraxanthin, when light is in excess. Both anther- axanthin and zeaxanthin have been shown to be responsible for the protective dissipation of excess excitation energy (Gilmore \& Yamamoto 1993). The relative proportions of the carotenoids of this cycle in hydrated green algal lichens seem to play a similar photoprotective role as they do in vascular plants (Demmig-Adams et al. 1990, Demmig-Adams \& Adams 1992). This avoidance of photoinhibitory damage by increasing the non-radiative energy dissipation appears to be the first response of plants to a variety of environmental stresses, and although exactly how heat dissipation is stimulated remains unknown, there is abundant evidence that violaxanthin de-epoxidation and PS II reaction center inactivation are involved (Schreiber et al. 1994).

The light conditions under which lichens grow in the field influence both their acclimation and recovery capacities to high light treatments (Manrique et al. 1993) and their photoprotection potential via xanthophyll cycle (Adams et al. 1993). Few ecophysiological studies of lichens have focussed on those periods of transition after precipitation events when hydrated thalli may be exposed, however briefly, to high light. The photosynthetic response pat- 
terns in relation to light have been mainly studied in hydrated thalli during actual periods of precipitation or under low energy conditions immediately thereafter (Kershaw \& Watson 1983), but there is evidence for the potential importance of those periods of transition following precipitation for the net photosynthesis of lichens in particular localities (Coxson 1987a). Negative effects of strong light on lichen photosynthesis were observed in tropical, temperate (Coxson 1987b), mediterranean (Manrique et al. 1993), and polar species (Kappen et al. 1991). Lichens growing in mediterranean climatic areas experience sudden increases in light after short precipitation events, especially during stormy periods of spring and summer. It has been observed that certain Spanish Umbilicariaceae significantly increased the upper surface albedo of their thalli when their water content was optimum for photosynthesis. It has been suggested that this change in the upper surface albedo could be adaptative protection against the deleterious effects of the high light that periodically follows precipitation in the mediterranean habitats where these species were found (Sancho et al. 1994). In mediterranean climates, lichens typically have a short metabolically active phase during the early morning hours following hydration during the night (Lange 1988; Lange et al. 1985). Due to the rarity of periods of activity, the response to sporadic precipitation events that are followed by high light could have a critical effect on the global carbon balance of lichens growing in mediterranean climate zones. The present experiment examines the diurnal course of photosynthetic efficiency and the changes in the proportions of xanthophyll pigments in artificially hydrated thalli of Anaptychia ciliaris (L.) Körber, a common lichen in certain mediterranean oak forests. The main goal was to assess the physiological response of this lichen to hydration under two contrasting light environments (sun and shade). Chlorophyll fluorescence analysis was employed here as it is now widely accepted as a reliable tool in order to assess in vivo photosynthesis and non-radiative energy dissipation under field conditions (Schreiber et al. 1994).

\section{Materials AND Methods}

Sampling and hydration treatments. - Field measurements were carried out in July 21, 1993, in a forest of deciduous oak (Quercus faginea Lam.) located near Piqueras (Guadalajara, Spain), where the lichen Anaptychia ciliaris (L.) Körber was abundant growing on tree bark. Prior to daybreak (5:30 local time), dry, medium-size thalli were collected and divided into two main groups, one to be placed under direct sunlight and the other one to be placed in the shade. Five thalli of each group were kept artificially hydrated during the entire experimental period. Another five thalli of each group were hydrated 15 minutes before the measurements, remaining dry until then. New sets of dry thalli were used each time to ensure that the samples were not partially hydrated during manipulations. The water content of non-hydrated samples was always inappreciable and the apparently dry status of the photobiont of these thalli was confirmed by non-detectable fluorescence signal (as in Schroeter et al. 1991). The hydration level of the lichens that were kept continuously wet was controlled by weighing them periodically and spraying with distilled water when necessary. Fluorescence measurements and sample collection for pigment extraction of thalli were achieved at 7:00, 11:00, 16:00, 20:00, and 23:00 local time.

Chlorophyll fluorescence.-Measurements of fast and slow chlorophyll fluorescence kinetics in vivo were made using a portable PAM-2000 fluorometer(Walz, Germany). Samples were dark-adapted for 15 minutes with a black fabric that was always kept wet to avoid both thallus dehydration and temperature increase as a consequence of the incoming radiation. In fact, the temperature under the fabric did not differ appreciably from the air temperature. This dark adaptation was carried out on hydrated samples and, consequently in the case of thalli kept dry in the different light environments, a different thallus sample was used and hydrated at each time for corresponding measurements. Afterwards, samples were illuminated with red, modulated light to measure the initial fluorescence (Fo), followed by a saturating pulse of $4,000 \mu \mathrm{mol}$ photons $\mathrm{m}^{-2}$ sec. ${ }^{-1}$ PAR, to obtain maximum fluorescence (Fm). Next, an actinic light of $350 \mu \mathrm{mol}$ photons $\mathrm{m}^{-2} \mathrm{sec}^{-1} \mathrm{PAR}$ was switched on for 4-6 minutes until a steady fluorescence signal (Ft) was reached. Then, the maximum fluorescence of light adapted samples ( $\left.\mathrm{Fm}^{\prime}\right)$ was measured. The following fluorescence variables were calculated: photosynthetic efficiency $\mathrm{Fv} / \mathrm{Fm}([\mathrm{Fm}-\mathrm{Fo}] / \mathrm{Fm})$, ratio of fluorescence decrease $(\mathrm{Rfd}=[\mathrm{Fm}-\mathrm{Ft}] / \mathrm{Ft}$, as in Haitz \& Lichtenthaler 1989), photochemical quenching ( $\mathrm{qP}=\left[\mathrm{Fm}^{\prime}-\mathrm{Ft}\right] /[\mathrm{Fm}$ $-\mathrm{Fo}])$ and non-photochemical quenching $(\mathrm{qN}=[\mathrm{Fm}-$ $\left.\mathrm{Fm}^{\prime}\right] /[\mathrm{Fm}-\mathrm{Fo}]$ ) of fluorescence (Jones 1992). Fv/Fm is used as an estimator of photoinhibition, $\mathrm{Rfd}$ as a vitality index, and the two quenchings as estimators of the dissipation of excitation energy through photochemical or non-photochemical processes. Due to the important effect of thallus water content on the fluorescence response of poikilohydric plants (Casper et al. 1993; Jensen \& Feige 1991; Manrique et al. 1993; Schroeter 1994), the ratio of variable to maximum fluorescence (Fv/Fm, Krause \& Weis 1991) during a dark dehydration course of five thalli of $A$. ciliaris was followed up in the laboratory prior to field measurements.

Pigment determination. - For carotenoid and chlorophyll extraction and quantification, small fragments of lichen thalli were collected at the beginning of each set of fluorescence measurements and plunged into liquid nitrogen to be transported to the laboratory. Twenty mg portions of each sample were submerged in $1 \mathrm{ml}$ of $\mathrm{N}, \mathrm{N}$ Dimethylformamide at $65^{\circ} \mathrm{C}$ for 40 minutes (as in Barnes et al. 1992; Speziale et al. 1984). Extracts were filtered through a Nylon-66 membrane (Millipore) with $0.45 \mu \mathrm{m}$ pore size and injected in a high performance liquid chromatography system (HPLC). A $10 \mu \mathrm{l}$ volume of each filtered extract was injected into a $250 \times 4.6 \mathrm{~mm}$ Spherisorb ODS- 2 column using a Rheodyne injector and eluted by passing solvent A (mixture of acetonitrile, methanol, and methylene chloride $96.5: 1.75: 1.75 \mathrm{v} / \mathrm{v})$ for 7 minutes and solvent B (mixture of acetonitrile and ethyl acetate 50:50 $\mathrm{v} / \mathrm{v}$ ) for another 7 minutes. The solvent change was done by means of a Y-valve. The flow was kept at a constant rate of $2 \mathrm{ml}$ minutes $^{-1}$. The combination of these two solvents allowed satisfactory separation of all carotenoids 


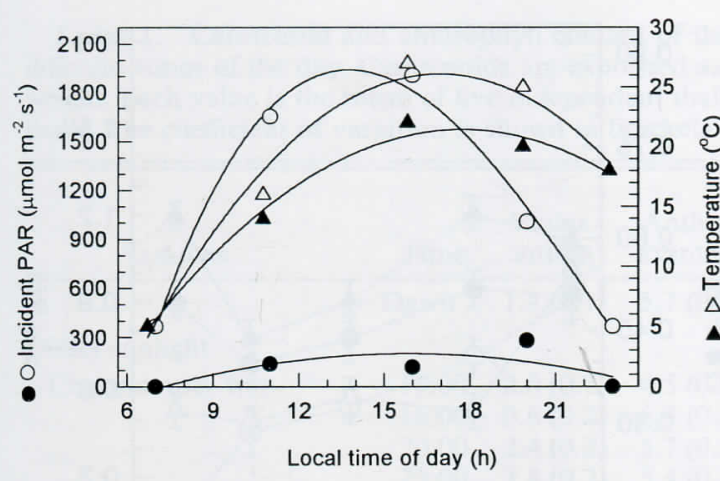

FIGURE 1. Light intensity (Photosynthetic Active Radiation, $\mu \mathrm{mol} \mathrm{m} \mathrm{m}^{-2} \mathrm{~s}^{-1}$ ) and air temperature $\left({ }^{\circ} \mathrm{C}\right)$ in the sunny site (open symbols) and in the shade (black symbols) at the begining of each measurement.

studied. The differentiation of zeaxanthin from luthein was not as accurate as that achieved with more expensive columns (e.g., Zorbax non-endcaped column, Thayer \& Björkman 1990), but it was clear enough to allow unbiased quantifications of both carotenoids. The detection was carried out at a wavelength of $440 \mathrm{~nm}$ with a $2550 \mathrm{UV}$ Detector Spectrophotometer (Varian Instruments), and the results processed with a DS-650 Series Data System Integrator (Varian Instruments). Standards of lutein, $\beta$-carotene, chlorophylls $a$ and $b$ (from Sigma Chemical Co), and zeaxanthin (from Hoffman-La Roche) were co-chromatographed for identification.

In preliminary chromatographies, each peak fraction of the lichen pigment extracts was collected separately at the outlet of the detector, passing them through a Sep-Pak $\mathrm{C}_{18}$ cartridge filter (Millipore) and concentrated by solvent evaporation under a nitrogen stream. Each fraction was dissolved in a solvent appropriate for their identification and quantification according to Davies (1976). The equations for the conversion of peak area units of each pigment into pigment weight per injected volume were obtained from regression analysis of solutions of known concentrations. All manipulations were carried out in the dark or under dim light. Further details are available in SanchezHoyos and Manrique (1995).

\section{RESULTS}

Incident Photosynthetically Active Radiation (PAR) and air temperature in the two localities at different times of the day of the field experiment are plotted in Figure 1. Constant values for photochemical efficiency of thalli of Anaptychia ciliaris, assessed by the fluorescence parameter Fv/Fm, were observed in the laboratory only above $50 \%$ of their maximum water content (Fig. 2) and consequently this hydration level was taken as the lower limit for reliable measurements in the field.

The photochemical efficiency of photosystem II decreased significantly throughout the day in wet thalli of Anaptychia ciliaris exposed to direct sunlight while it increased, although slightly, in wet thalli kept in the shade (Fig. 3). The vitality of the

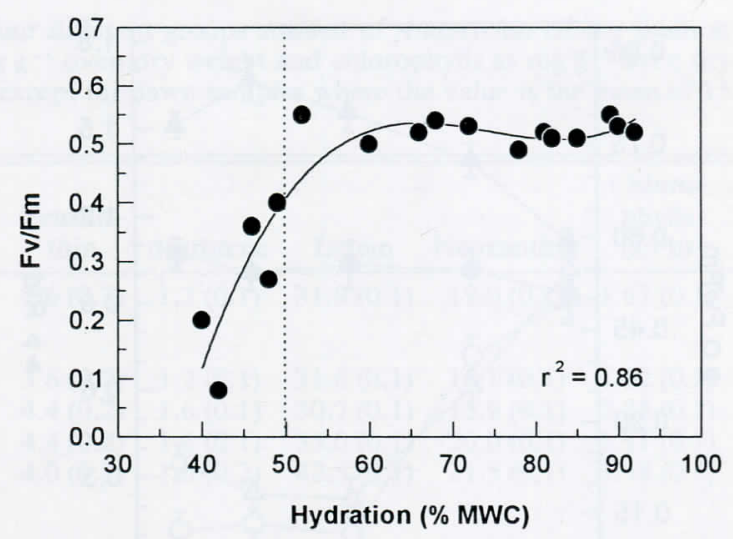

FIGURE 2. Ratio of variable to maximum fluorescence $(\mathrm{Fv} / \mathrm{Fm})$ in the dark as a function of thallus hydration expressed as percentage of maximum water content (MWC) in five thalli of Anaptychia ciliaris. Dotted line indicates the lower limit of thallus hydration (50\%) accepted in the present study for reliable fluorescence measurements.

photosystem II, assessed by the fluorescence index $\mathrm{Rfd}$, decreased throughout the day in wet thalli exposed to direct sunlight but it increased in wet thalli kept in the shade towards the end of the day. The non-photochemical quenching $(\mathrm{qN})$ decreased in the late afternoon in wet, shade thalli but it increased drastically after midday in wet thalli exposed to direct sunlight. Coinciding with the decrease in photochemical efficiency and the increase in $\mathrm{qN}$ in these thalli, the relative proportions of antheraxanthin (A) and zeaxanthin $(\mathrm{Z})$ showed a significant increase in the afternoon (Fig. 3). Nevertheless, the xanthophyll pool of these thalli recovered its predawn values in the late evening and the relative amounts of $\mathrm{A}+\mathrm{Z}$ at night were even smaller than at predawn, while the values of $\mathrm{Fv} / \mathrm{Fm}$ and $\mathrm{Rfd}$ of these samples remained very low during the afternoon and the evening without recovering predawn values. The relative amounts of $\mathrm{A}+\mathrm{Z}$ exhibited a continuous decrease throughout the day in wet, shaded thalli which was correlated with the increase in $\mathrm{Fv} / \mathrm{Fm}$ and $\mathrm{Rfd}$. The photochemical quenching (qP) showed little diurnal variations and no large differences between these two groups of thalli.

Dry thalli exposed to direct sunlight and hydrated 15 minutes before the measurement showed similar diurnal changes in their fluorescence response and relative proportions of xantophyll pool pigments (Fig. 4) to the thalli continuously wet under the same high light (Fig. 3). Nevertheless, the values of Fv/ Fm and Rfd of these lichens were slightly higher in the afternoon than they were at that time in their counterparts kept wet all day long. Analogously, dry thalli kept in the shade and hydrated 15 minutes before the measurement showed similar diurnal 


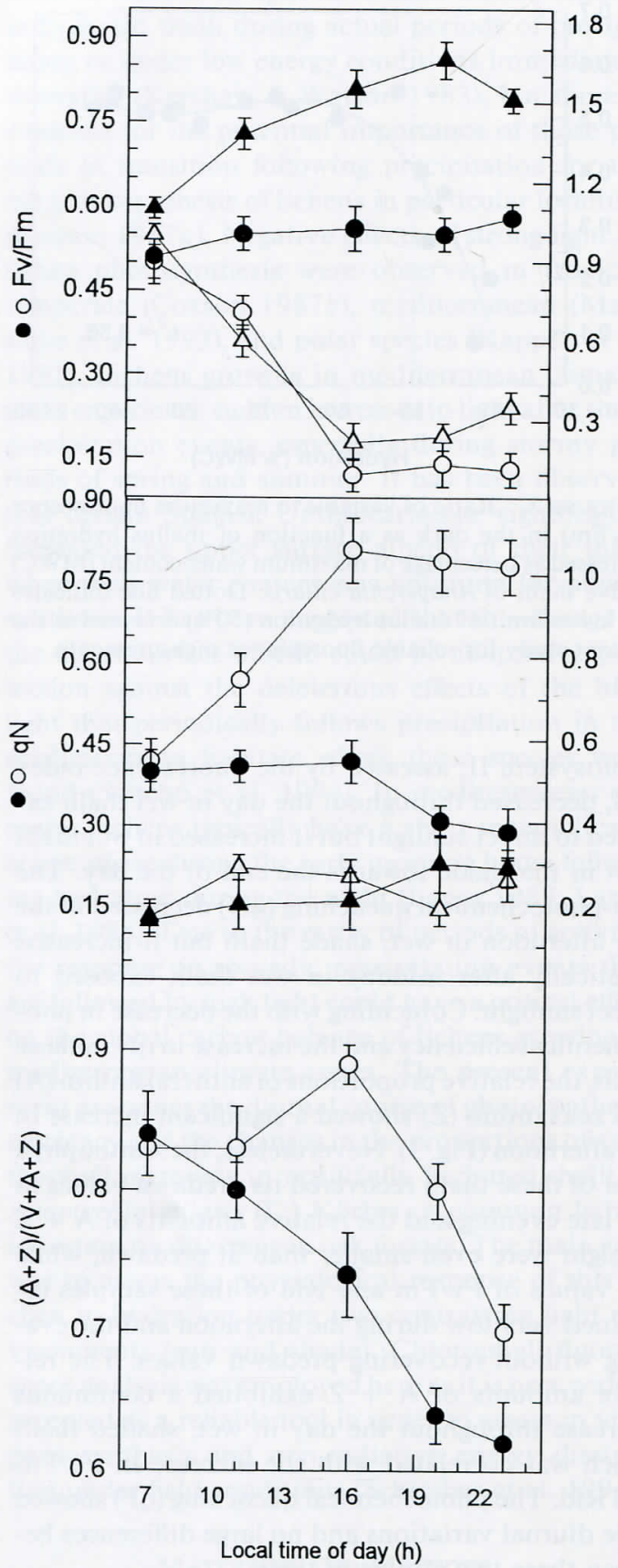

FIGURE 3. Diurnal changes of Fv/Fm, ratio of fluorescence decrease ( $\mathrm{Rfd}$ ), non-photochemical and photochemical quenchings ( $\mathrm{qN}$ and $\mathrm{qP}$, respectively), and antheraxanthin plus zeaxanthin content in relation to the xanthophyll pool $(\mathrm{A}+\mathrm{Z} / \mathrm{V}+\mathrm{A}+\mathrm{Z})$ of thalli of $A n$ aptychia ciliaris kept wet during the entire day. Open symbols represent thalli kept under sunlight and black symbols represent thalli kept in the shade. Each point is the mean of five thalli and vertical bars represent standard deviation.

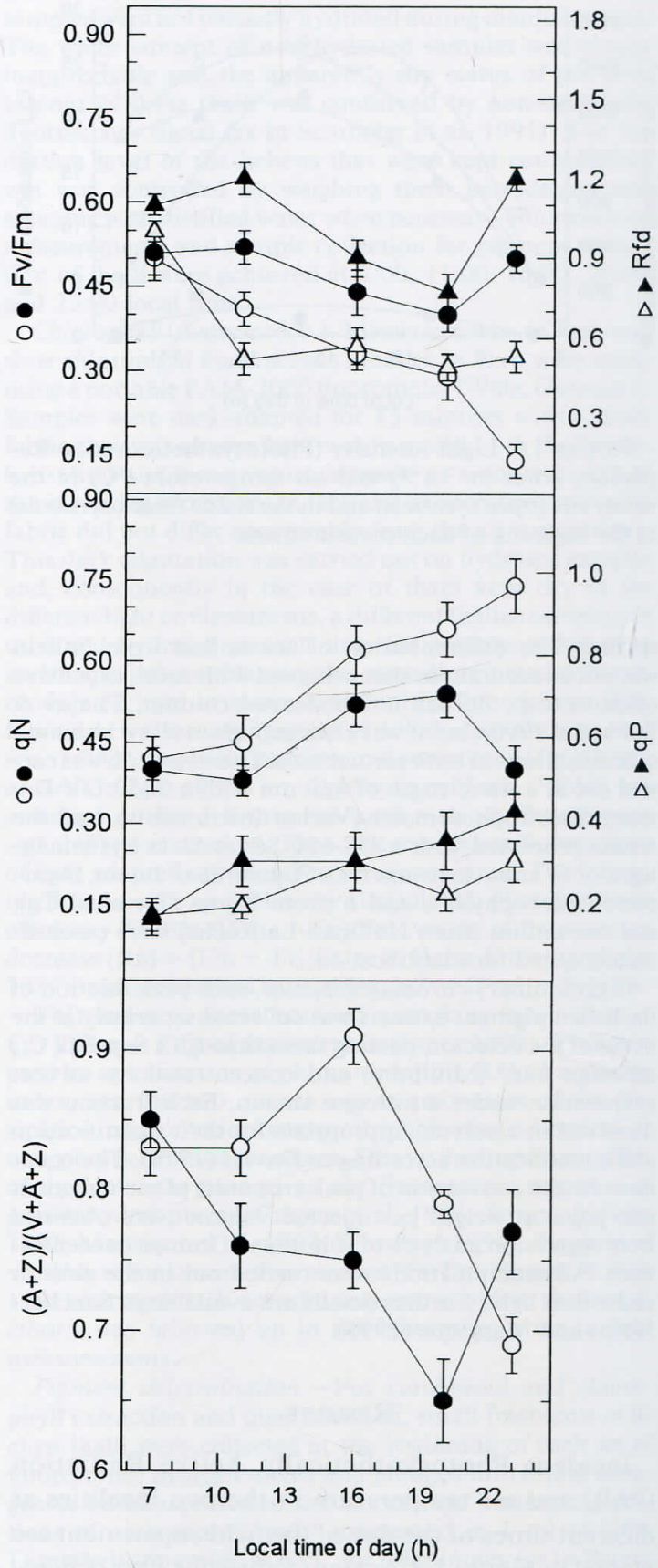

FIGURE 4. Diurnal changes of Fv/Fm, ratio of fluorescence decrease ( $\mathrm{Rfd})$, non-photochemical and photochemical quenchings ( $\mathrm{qN}$ and $\mathrm{qP}$, respectively), and antheraxanthin plus zeaxanthin content in relation to the xanthophyll pool $(\mathrm{A}+\mathrm{Z} / \mathrm{V}+\mathrm{A}+\mathrm{Z})$ of thalli of $A n$ aptychia ciliaris kept dry and hydrated only 15 minutes before measurements. Open symbols represent thalli kept under sunlight and black symbols represent thalli kept in the shade. Each point is the average of five thalli and vertical bars represent standard deviation. 
TABLE 1. Carotenoid and chlorophyll content of the four different groups studied of Anaptychia ciliaris thalli at different times of the day. Carotenoids are expressed as $\mu \mathrm{g} \mathrm{g}^{-1}$ oven dry weight and chlorophylls as $\mathrm{mg} \mathrm{g}^{-1}$ oven dry weight. Each value is the mean of five independent thalli, except for dawn samples where the value is the mean of 15 thalli. The coefficient of variation is shown in brackets.

\begin{tabular}{|c|c|c|c|c|c|c|c|c|}
\hline Samples & Time & $\begin{array}{l}\text { Violax- } \\
\text { anthin }\end{array}$ & $\begin{array}{l}\text { Anther- } \\
\text { axanthin }\end{array}$ & $\begin{array}{c}\text { Zeaxan- } \\
\text { thin }\end{array}$ & $\beta$ carotene & Lutein & Neoxanthin & $\begin{array}{l}\text { Chloro- } \\
\text { phylls } \\
(\mathrm{a}+\mathrm{b})\end{array}$ \\
\hline & Dawn & $1.4(0.1)$ & $5.7(0.1)$ & $2.6(0.2)$ & $1.2(0.1)$ & $31.9(0.1)$ & $19.0(0.1)$ & $1.67(0.1)$ \\
\hline \multicolumn{9}{|l|}{ Direct sunlight } \\
\hline \multirow[t]{4}{*}{ Continuously wet } & $11: 00$ & $2.0(0.2)$ & $4.5(0.1)$ & $3.6(0.2)$ & $1.2(0.1)$ & $31.8(0.1)$ & $16.1(0.1)$ & $1.82(0.1)$ \\
\hline & $16: 00$ & $0.6(0.2)$ & $6.3(0.2)$ & $4.4(0.2)$ & $1.6(0.1)$ & $30.7(0.1)$ & $15.9(0.1)$ & $2.85(0.1)$ \\
\hline & 20:00 & $2.4(0.2)$ & $5.7(0.2)$ & $4.4(0.2)$ & $1.6(0.1)$ & $33.0(0.1)$ & $20.0(0.1)$ & $1.91(0.1)$ \\
\hline & 23:00 & $3.8(0.2)$ & $5.4(0.2)$ & $4.0(0.2)$ & $1.6(0.2)$ & $42.5(0.1)$ & $21.5(0.1)$ & $1.58(0.1)$ \\
\hline \multicolumn{9}{|l|}{ In shade } \\
\hline \multirow[t]{4}{*}{ Continuously wet } & $11: 00$ & - & - & - & - & - & - & - \\
\hline & $16: 00$ & $3.7(0.1)$ & $7.0(0.1)$ & $3.2(0.1)$ & $1.6(0.1)$ & $38.9(0.1)$ & $22.5(0.1)$ & $3.67(0.1)$ \\
\hline & $20: 00$ & $4.4(0.1)$ & $5.0(0.1)$ & $3.2(0.1)$ & $1.4(0.1)$ & $33.0(0.1)$ & $18.5(0.1)$ & $1.75(0.2)$ \\
\hline & 23:00 & $5.5(0.1)$ & $5.4(0.1)$ & $3.6(0.1)$ & $1.8(0.1)$ & $43.7(0.1)$ & $23.5(0.1)$ & $1.51(0.1)$ \\
\hline \multicolumn{9}{|l|}{ Direct sunlight } \\
\hline \multirow[t]{4}{*}{15 minutes of hydration } & $11: 00$ & $3.5(0.1)$ & $8.1(0.1)$ & $4.8(0.1)$ & $1.8(0.1)$ & $43.1(0.1)$ & $23.0(0.1)$ & $2.59(0.2)$ \\
\hline & $16: 00$ & $1.6(0.1)$ & $9.0(0.1)$ & $7.2(0.1)$ & $1.8(0.1)$ & $52.5(0.1)$ & $26.1(0.1)$ & $1.65(0.2)$ \\
\hline & $20: 00$ & $2.9(0.1)$ & $7.6(0.1)$ & $3.2(0.1)$ & $1.6(0.1)$ & $35.4(0.1)$ & $19.0(0.1)$ & $1.66(0.2)$ \\
\hline & $23: 00$ & $5.5(0.1)$ & $8.5(0.1)$ & $3.6(0.1)$ & $1.8(0.1)$ & $44.8(0.1)$ & $25.5(0.1)$ & $1.30(0.2)$ \\
\hline \multicolumn{9}{|l|}{ In shade } \\
\hline \multirow[t]{4}{*}{15 minutes of hydration } & $11: 00$ & $2.4(0.1)$ & $4.6(0.1)$ & $3.2(0.1)$ & $0.9(0.2)$ & $36.0(0.1)$ & $19.0(0.1)$ & $1.27(0.2)$ \\
\hline & $16: 00$ & $2.9(0.1)$ & $7.5(0.1)$ & $3.6(0.1)$ & $1.4(0.2)$ & $44.2(0.2)$ & $23.5(0.1)$ & $2.46(0.2)$ \\
\hline & $20: 00$ & $5.1(0.1)$ & $6.7(0.1)$ & $2.8(0.1)$ & $1.4(0.2)$ & $36.0(0.1)$ & $22.1(0.1)$ & $1.94(0.2)$ \\
\hline & 23:00 & $3.6(0.1)$ & $8.2(0.1)$ & $3.2(0.1)$ & $1.6(0.2)$ & $42.5(0.1)$ & $22.0(0.1)$ & $1.45(0.2)$ \\
\hline
\end{tabular}

changes in the parameters studied (Fig. 4) to thalli kept continuously wet in the shade (Fig. 3), although the diurnal trend toward an increase in $\mathrm{Fv} / \mathrm{Fm}$ and Rfd with a parallel decrease in the relative amounts of $\mathrm{A}+\mathrm{Z}$ was less clear in these group of samples.

The general carotenoid composition and chlorophyll content of all groups of samples are shown in Table 1. On average, the xanthophyll cycle pigments (violaxanthin + antheraxanthin + zeaxanthin) represented $16 \%$ of total carotenoids, while the most abundant was lutein $(51 \%)$, followed by neoxanthin (31\%). $\beta$-carotene represented only $2 \%$ of the total carotenoids, and only trace levels of $\alpha$-carotene were detected. No significant diurnal trends were observed in the pigment content of the samples, with the already mentioned exception of the xanthophyll pool relative proportions.

\section{DISCUSSION}

Our results show an important diurnal increase in thermal energy dissipation, with a parallel decrease in photosynthetic efficiency in all thalli of Anaptychia ciliaris exposed to direct sun, regardless of the hydration treatment. The thalli kept in the shade exhibited almost the inverted diurnal trend (decrease in thermal energy dissipation and increase in photosynthetic efficiency) and, again, the trend was similar for continuously wet samples and samples hydrated 15 minutes before the measurements. These similarities found between the samples kept continuously wet and those hydrated 15 minutes before the measurements point to a relatively rapid response of lichens to the light environment once they are metabolically active. They also point to the unexpected finding that dry thalli exposed to direct sunlight and hydrated only under the very low light of the late evening showed similar values for the parameters studied to those of their counterparts kept continuously wet under the sunlight (Figs. 34). Non-hydrated thalli were checked by chlorophyll fluorescence and non-detectable activity of green algal PSII was observed, which has been considered an indication of dry and inactive lichen photobionts (Schroeter 1994; Schroeter et al. 1991, 1992). But perhaps some lichens dried in their natural environments still have enough water for some metabolic processes. The fast response of the photobiont of $A$. ciliaris to high light intensity found here agrees with what has been suggested from the carotenoid analysis of Umbilicaria vellea thalli that were briefly hydrated under direct sun light (Adams et al. 1993), and seems to be an advantageous feature for a poikilohydric organism that is subjected to intermitent and brief periods of activity.

The diurnal course of the fluorescence parameters 
of all thalli of $A$. ciliaris kept in the shade proves the good adaptation of this lichen to understory light conditions, since they exhibited optimum values of vitality and photochemical efficiency of PS II despite the artificial hydration treatments that they were subjected to. The fact that shade thalli increased their Rfd values and, to a lesser extent, also their Fv/Fm values throughout the day was clearly associated with a decrease in the thermal energy dissipation and the relative amount of antheraxanthin and zeaxanthin.

The predawn measurements pointed to a sustained thermal energy dissipation in the studied thalli of $A$. ciliaris, evidence by low values of $\mathrm{Fv} / \mathrm{Fm}$ and relatively high values of $(A+Z) /(V+A+Z)$ (Fig. 3-4). Adams et al. (1993) reported high accumulations of $\mathrm{Z}$ for shade thalli of several lichen species and they argued that dessication of lichens in the shade could lead to reductions in photosynthesis rates such that even the low intensity of light found in such an environment may become excessive, stimulating the formation of large amounts of this pigment. An accumulation of $\mathrm{A}+\mathrm{Z}$ has been found in the lichen Ramalina capitata during the dessication process that was relatively independent of the light intensity at the moment of dessication (Sanchez-Hoyos \& Manrique 1995). This suggests the possible existence of a general accumulation of the photoprotective forms of the xanthophyll cycle during the process of thallus dessication, although the role of the low light suggested by Adams et al. (1993) cannot be ruled out. Another possible explanation for the high predawn levels of $A+Z$ observed in A. ciliaris is the chilling night and predawn temperatures registered in the study area even in summer (Fig. 2). A photoprotective down regulation of PS II that involved xanthophyll cycle associated energy dissipation sustained throughout the night has been found in plants exposed to low temperatures (Adams \& Demmig-Adams 1994), but it has not been studied in lichens. The reduction in the photochemical efficiency caused by high light at chilling temperatures observed in lichens (Coxson $1987 a, b)$ and vascular plants (Huner et al. 1993) seems to be an infrequent event for the lichen studied here since low temperatures are mostly associated with low light intensities in the shade localities where $A$. ciliaris occurs. But nevertheless, the low predawn photochemical efficiency observed in $A$. ciliaris could be an important restriction for the general carbon gain of this lichen due to its negative effect on net photosynthetic rate under non-saturating light and due to the fact that it is precisely in the early morning when lichens typically exhibit a short period of high photosynthesis under mediterranean climatic conditions (Lange 1988, Lange et al. 1985). Any environmental factor decreasing the speed of the interconversion of the xanthophyll cycle pigments (e.g., cold temperatures, low thallus water content) would have a detrimental effect on the utilization efficiency of these short hydration periods, since both the maintenance of high levels of $\mathrm{A}+\mathrm{Z}$ under low light conditions (decreased photosynthetic efficiency) and the inability for a fast production of $\mathrm{A}+\mathrm{Z}$ under high light (decreased photoprotection, increased risk of photon damage) may have equally dramatic implications for the growth of this lichen species.

The Fv/Fm values of all thalli of $A$. ciliaris exposed to direct sunlight during the whole day were very low after several hours at low light during the evening despite the low values of $A+Z$ observed at that time of day. The sustained high non-photochemical quenching of these thalli showed by chlorophyll fluorescence was due not only to a real thermal energy dissipation (associated with a quenching of the maximal fluorescence) but also to an increase in the minimal fluorescence (Fo). These facts together point to a possible chronic photoinhibition (photon damage) of these samples, and may indicate the deleterious effect of an artificially long exposure to direct sunlight of $A$. ciliaris thalli from the studied population. It would be interesting to study the possible existence of photochemical acclimation of this lichen to direct sunlight and the possible development of long-term adaptations concerning pigment content and thallus morphology that would allow this lichen to cope with high light intensities. The apparent photon damage observed in the samples exposed throughout the day to direct sunlight but hydrated only under dim light in the late evening may reflect a maintenance of a very low metabolic activity in some apparently dry lichens (and then, photoinhibitory damage due to the absorptance of more light than used in photochemistry) as discussed above. But it may also reflect a malfunction under the experimental conditions of the photoprotective process suggested for dessicated lichens (Bilger et al. 1989; Sigfridsson \& Öquist 1980).

The sunlight treatment studied here resembles, to a certain extent, the rapid and dramatic changes in the canopy that occassionally take place in some open forests and woodlands in mediterranean habitats affected by human management. The observed disappearence of $A$. ciliaris in some of these localities could be associated with a detrimental frequency of photoinhibitory damage events for these shade-acclimated populations.

\section{ACKNOWLEDGMENTS}

We are grateful to Francisca Sojo and Estela Seriñá for help during field sample and data collection. Thanks to Martina Königer for helpful criticisms and to Kelly Lyon 
for polishing the English. This manuscript has benefited from fitting comments of Barbara Demmig-Adams.

\section{Literature Cited}

Adams III, W. W. \& B. Demmig-Adams. 1994. Carotenoid composition and down regulation of photosystem II in three conifer species during winter. Physiologia Plantarum 92: 451-458.

\& O. L. LANGE. 1993. Carotenoid composition and metabolism in green and blue-green algal lichens in the field. Oecologia 94: 576-584.

BAKER, N. R. \& J. R. BOWYER. 1994. Photoinhibition of photosynthesis. Bios Scientific Publishers. Oxford.

Barnes, J. D, L. Balaguer, E. Manrique, S. Elvira \& A. W. DAvison. 1992. A reappraisal of the use of DMSO for the extraction and determination of chlorophyll $\mathrm{a}$ and $\mathrm{b}$ in lichens and higher plants. Environmental and Experimental Botany 32: 85-100.

Bilger, W., S. Rimke, U. SChreiber \& O. L. LANGE. 1989. Inhibition of energy transfer to photosystem II in lichens by dehydration: different properties of reversibility with green and blue-green phycobionts. Journal of Plant Physiology 134: 261-268

CASPer, C., W. G. Eickmeier \& C. B. Osmond. 1993. Changes of fluorescence and xanthophyll pigments during dehydration in the resurrection plant Selaginella lepidophylla in low and medium light intensities. Oecologia 94: 528-533.

Coxson, D. S. 1987a. The temperature dependence of photoinhibition in the tropical basidiomycete lichen Cora pavonia E. Fries. Oecologia 73: 447-453.

- $1987 \mathrm{~b}$. Photoinhibition of net photosynthesis in Stereocaulon virgatum and $S$. tomentosum, a tropicaltemperate comparison. Canadian Journal of Botany 65: 1707-1715.

DAviEs, B. H. 1976. Carotenoids. pp. 159-183. In T. W. Goodwin (ed.), Chemistry and Biochemistry of Plant Pigments, vol. 2 Academic Press. New York.

Demmig-Adams, B. \& W. W. Adams, III. 1992. Photoprotection and other responses of plants to high light stress. Annual Review of Plant Physiology and Plant Molecular Biology 43: 599-626.

- C. Maguas, W. W. Adams, III, A. Meyer, E. KILIAN \& O. L. LANGE. 1990. Effect of high light on the efficiency of photochemical energy conversion in a variety of lichen species with green and blue-green phycobionts. Planta 180: 400-409.

Demmig, B., K. Winter, A. Kruger \& F. C. Czygan. 1987. Photoinhibition and zeaxanthin formation in intact leaves. A possible role of the xanthophyll cycle in the dissipation of excess light energy. Plant Physiology 84: 218-224.

Gilmore, A. M. \& H. Yамамото. 1993. Linear models relating xanthophylls and lumen acidity to non-photochemical fluorescence quenching. Evidence that antheraxanthin explains zeaxanthin-independent quenching. Photosynthesis Research 35: 67-78.

Haitz, M. \& H. K. LichtenthaleR. 1989. The measurement of Rfd-values as plant vitality indices with the portable field chlorophyll fluorometer and the PAMfluorometer, pp. 249-254. In H. K. Lichtenthaler (ed.), Applications of Chlorophyll Fluorescence. Kluwer Academic Publishers Dordrecht.

Huner, N. P. A., G. ÖQuist, V. M. Hurry, M. Krol, S. FALK \& M. GRIFFITH. 1993. Photosynthesis, photoinhibition and low temperature acclimation in cold tolerant plants. Photosynthesis Research 37: 19-39.
Jensen, M. \& G. B. Feige. 1991. Quantum efficiency and chlorophyll fluorescence in the lichens Hypogymnia physodes and Parmelia sulcata. Symbiosis 11:179191.

JoNes, H. G. 1992. Plants and Microclimate. Cambridge University Press. Cambridge.

KAPPEN, L., M. BReUER AND M. Bölter. 1991. Ecological and physiological investigations in continental antarctic cryptogams. Polar Biology 11: 393-401.

Kershaw, K. A. \& S. WATSON. 1983. The control of seasonal rates of net photosynthesis by moisture, light and temperature in Parmelia disjuncta Erichs. THE BRYOLOGIST 86: 31-43.

Krause, G. H. \& E. Weis. 1991. Chlorophyll fluorescence and photosynthesis: The basics. Annual Review of Plant Physiology and Plant Molecular Biology 42: 313-349.

LANGE, O. L. 1988. Ecophysiology of photosynthesis: performance of poikilohydric lichens and homoiohydric mediterranean schlerophylls. Journal of Ecology 76: 915-937.

- J. D. Tehnunen, P. Harley \& H. Walz. 1985. Methods for field measurements of $\mathrm{CO}_{2}$ - exchange. The diurnal changes in net photosynthesis and photosynthetic capacity of lichens under mediterranean climatic conditions, pp. 23-39. In D. H. Brown (ed.), Lichen Physiology and Cell Biology. Plenum Publishing. New York.

Manrique, E., L. Balaguer, J. Barnes \& A. W. Davison. 1993. Photoinhibition studies in lichens using chlorophyll fluorescence analysis. THE BRYOLOGIST 96: 443449.

Osmond, C. B. 1994. What is photoinhibition? Some insights from comparisons of sun and shade plants, pp. 1-24. In N. R. Baker \& J. R. Bowyer (eds.), Photoinhibition of Photosynthesis, Bios Scientific Publishers. Oxford.

Powles, S. B. 1984. Photoinhibition of photosynthesis induced by visible light. Annual Review of Plant Physiology and Plant Molecular Biology 1984: 15-44.

SANChez-Hoyos, M. A. \& E. ManRiQue. 1995. Effect of nitrate and ammonium ions on the pigment content (xanthophylls, carotenes and chlorophylls) of Ramalina capitata. Lichenologist 27: 155-160.

Sancho, L. G., F. Valladares \& C. Ascaso. 1994. Effect of hydration on colour and temperature in thalli of Umbilicariaceae. Cryptogamic Botany 4: 227-232.

SChreiber, U., W. Bilger \& C. Neubauer. 1994. Chlorophyll fluorescence as a nonintrusive indicator for rapid assessment of in vivo photosynthesis, pp. 4969. In E. D. Schultze \& M. M. Caldwell (eds.), Ecophysiology of Photosynthesis. Ecological Studies 100. Springer Verlag. Berlin-Heidelberg.

SCHROETER, B. 1994. In situ photosynthetic differentiation of the green algal and the cyanobacterial photobiont in the crustose lichen Placopsis contortuplicata. Oecologia 98: 212-220.

—, T. G. A. Green, R. D. Seppelt \& L. Kappen. 1992. Monitoring photosynthetic activity of crustose lichens using a PAM-2000 fluorescence system. Oecologia 92: $457-462$.

$\longrightarrow$ C. Moldaenke \& L. KaPPen. 1991. Continuous in situ recording of the photosynthetic activity of antarctic lichens-established methods and a new approach. Lichenologist 23: 253-265.

Speziale, B. J., S. P. Schreiner, P. A. Giammatteo, \& J. E. SCHINDLER. 1984. Comparison of N, N-dimethylformamide, dimethyl sulfoxide and acetone for ex- 
traction of phytoplankton chlorophyll. Canadian Journal of Fisheries and Aquatic Science 41: 1519-1522.

Sigfridsson, B. \& G. ÖQUIST. 1980. Preferential distribution of excitation energy into photosystem I of desiccated samples of the lichen Cladonia implexa and the isolated lichen-alga Trebouxia pyriformis. Physiologia Plantarum 49: 329-335.

THAYER, S. S. \& O. BJörKMAN. 1990. Leaf xanthophyll content and composition in sun and shade determined by HPLC. Photosynthetic Research 23: 311-343. 